\title{
nature
}

18 November 2004 Volume 432 Issue no 7015

\section{Clean, green conferencing}

Big conferences are good for science. But because many researchers fly in, these events are also bad for the environment. What can be done to redress the balance?

C onsider this contradiction. Compared with most other professions, scientists are probably better informed and more concerned about climate change. Yet they also fly more than most, generating significant greenhouse-gas emissions. Last month, for example, 31,000 neuroscientists descended upon San Diego for their annual meeting. Even many of those based in the United States flew in.

Researchers should consider what to do about this, because politicians are unlikely to take any action. In countries that have signed the Kyoto Protocol, companies are starting to cut emissions through carbon-trading schemes. But airlines will not join the party, because aviation exhaust gases will lie outside the Kyoto Protocol until at least 2012. That's a problem: the sector generates $3.5 \%$ of global emissions, and its contribution is expected to double in the next 15 years.

What should scientists do? Some advice is as well worn as it is tough to take: think about going by train, bike or camel, or whether to go at all. These are not palatable ideas. Conferences are often too distant to reach, except by plane, but good science depends on the exchange of ideas. Nonetheless, it would be worth research groups considering whether they can send fewer members to conferences, and whether more distant and less important meetings can be missed altogether.

One alternative to missing events is to tot up the total emissions incurred by a flight, and invest in small-scale projects to cancel out the emissions. This could involve cutting carbon from other sources, by paying for solar panels, for example, or giving villagers in the developing world stoves that burn more cleanly. The web is teeming with companies that will calculate your next trip's emissions, work out how much it will cost to cut these emissions from other sources (see News Feature, page 268) and invest that amount in selected projects. Bingo - clean, green conferencing.

Some research organizations, such as the Tyndall Centre for Climate Change Research in Norwich, UK, already do this on a routine basis without incurring significant costs. Other institutes should consider following suit. Alternatively, academic societies might choose to add the costs to the meeting fees.

But before doing so, take a good look at the companies that offer to do this 'carbon offsetting. The problem is verification. Under Kyoto, companies can invest in well regulated mitigation projects, such as schemes to collect methane from landfill sites. Until offsetting projects are regulated in the same way, there is no guarantee that the firms involved have done their homework. Many offer to plant trees, for example, but forestry is not an accepted emissions-management strategy under Kyoto, partly because it offers no long-term guarantee of soaking up carbon. Trees can be cut down or burnt, especially if local people need them for fuel or economic gain.

To avoid such pitfalls, ask offsetting companies a few questions before investing. How transparent are they? Do they, for example, ask independent scientists to scrutinize their projects? And do they take a truly international outlook? There is little point in restricting investment to schemes in one particular country, as some companies do. Before you invite your colleagues to jet over to your own carbonneutral conference, make sure that it actually is.

\section{A chance for growth}

With the right safeguards, a national institute could give a much-needed boost to agricultural research in the United States.

$D$ lans are afoot to create more fertile pastures for research within the US Department of Agriculture (USDA). A proposed National Institute for Food and Agriculture, which could eventually have as much as $\$ 1$ billion a year to spend, would be associated with the USDA, but operate independently of it.

At first sight, this seems like a good opportunity to reinvigorate US agricultural research. Science at the USDA has been hamstrung for years, not by a lack of funding but by structural problems. Only about $15 \%$ of its $\$ 2$-billion annual research spend goes to competitive grants; the figure at the National Institutes of Health $(\mathrm{NIH})$ is $70 \%$. Some researchers are wary of the USDA's research programmes, fearing that they lack a long-term strategy. Farmers, consumers, researchers and agribusiness would all benefit if more of the cash went on competitive, peer-reviewed grants.

Advocates of the proposed institute, which is likely to be considered by Congress this month, say it could do this by operating along the same lines as the NIH, which has a long tradition of distributing grants on the basis of merit, without interference from its parent, the Department of Health and Human Services, or from the Congress.

But matters are unlikely to be so straightforward at the USDA, in part because agribusiness is accustomed to exercising a strong influ- ence over the department. It has championed the institute's creation and may expect to retain influence over its research programmes.

To constrain that influence and ensure the institute's independence, some minimum conditions must be met: its director should be a reputable and independent scientist, for example, and so should the members of its advisory panel. These people will put their reputations on the line when they take up their posts, and that should ensure they form a bulwark against commercial interference.

Harder to guarantee will be an understanding on the part of the congressional committees that fund the USDA that the new institute is to be left alone. In the past, the USDA's competitive, peer-reviewed research programmes have been eroded by a culture that demands that each politician receive something for the state they represent.

The committees should consider what the institute stands to lose if they do not take a hands-off approach. The institute is expected to tackle contentious questions on food, its relation to human health, and environmental issues. These questions can only be answered effectively by an institute that has the trust of the public. Equally importantly, the answers will only be accepted internationally if the institute is seen to take on the toughest questions and report the results honestly, irrespective of the corporate economic impact. 